\title{
Endoscopic radial incision and cutting method for refractory stricture of a rectal anastomosis after surgery
}

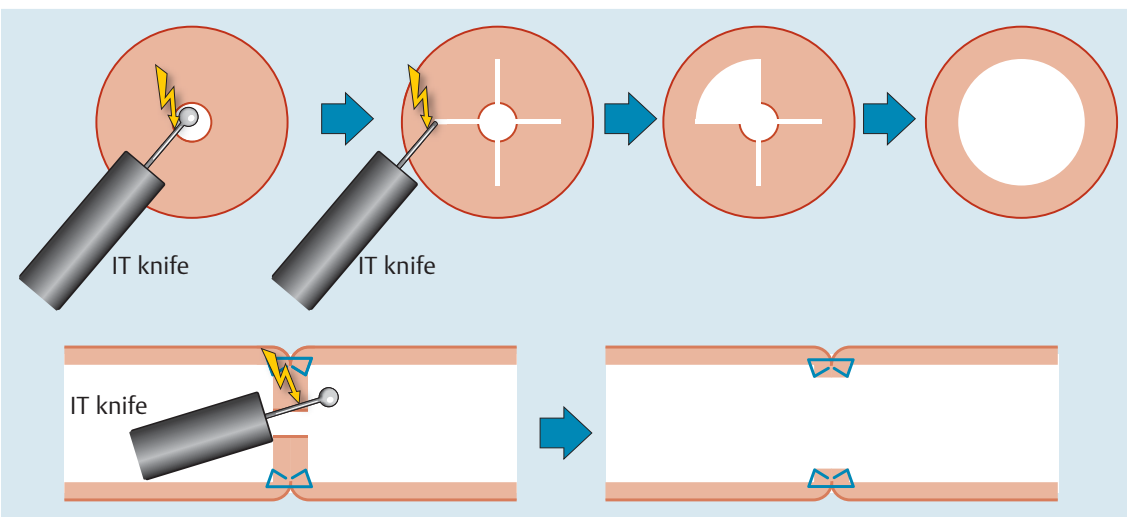

Fig. 1 Radial incision and cutting of a rectal anastomotic stricture: upper and lower diagrams show, respectively, the cross-section and longitudinal section of the rectal stricture site. The blue marks represent staples at the anastomosis. First, four or more incisions are made into the stricture site. Second, the flaps formed by the incisions are sliced off. Staples are good landmarks for determining the depth of the cutting line. IT, insulation-tipped.

Benign colorectal strictures occur mainly as a result of surgical resection [1]. Especially when a stricture is located in the rectum, it may cause severe symptoms, for which several therapeutic options are available: endoscopic balloon dilation (EBD) [2], placement of a self-expandable metal stent [3], revisional surgery, and palliative colostomy. However, the best treatment has yet to be determined.

The technique of endoscopic radial incision and cutting (RIC) was recently developed for refractory benign esophageal stricture [4]. In our present report, we describe four sessions of RIC in three patients with rectal anastomotic strictures that were refractory to conventional EBD and repetitive mechanical or finger bougie dilation. To the best of our knowledge, there have been few reports of the application of RIC other than in the esophagus. RIC was performed following the original method ( $\bullet$ Fig. 1) [5]. An insulation-tipped (IT) knife-1 (Olympus Medical, Tokyo, Japan) alone was used for all of the RIC sessions, and the setting of the electrosurgical unit was Endo Cut mode (Effect 1, 60 W, VIO 300; Erbe Elektromedizin, Tübingen, Germany).

All of the three patients were male with a median age of 62 years. They had undergone curative, laparoscopically assisted low or super-low anterior resection and diverting ileostomy for rectal tumor; two of the patients had advanced cancer, and the other had a gastrointestinal stromal tumor (GIST). Two of the three patients experienced difficult defecation after

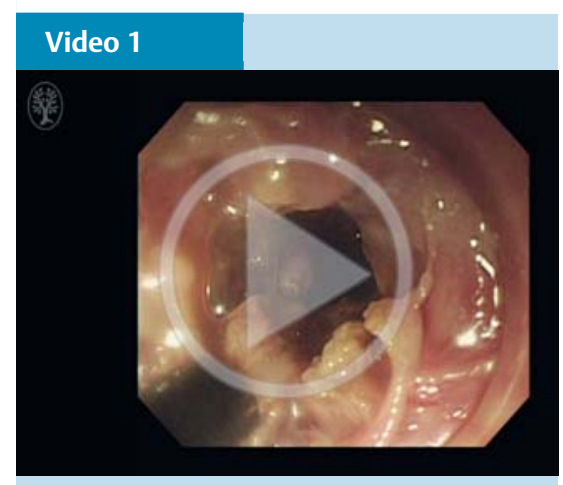

Procedure of radial incision and cutting for rectal anastomotic stricture in case 2 . ileostomy closure surgery, and in the patient with GIST, complete obstruction at the anastomosis had been diagnosed by radiographic contrast enema before ileostomy closure.

The results of RIC are shown in Table 1. In each case, the patient was treated without any complications, and adequate and long-term patency was achieved despite refractory strictures ( $\bullet$ Fig. 2, $\bullet$ Video 1 ). The patients have undergone monthly or semimonthly rectal examinations since RIC, and several months have passed without the need for additional dilation. We suggest that RIC is a novel option for refractory rectal anastomotic stricture.

Endoscopy_UCTN_Code_TTT_1AQ_2AF

\begin{tabular}{|c|c|c|c|c|}
\hline Patient & Timing of RIC & $\begin{array}{l}\text { Procedure } \\
\text { duration, min }\end{array}$ & $\begin{array}{l}\text { Length of hospitaliza- } \\
\text { tion after procedure, } d\end{array}$ & Follow-up period \\
\hline 1 (first procedure) & $\begin{array}{l}7 \text { mo after ileostomy } \\
\text { closure }\end{array}$ & 82 & 4 & 5 mo to re-stenosis \\
\hline 1 (second procedure) & 5 mo after first RIC & 35 & 3 & $\begin{array}{l}12 \text { mo to tumor } \\
\text { recurrence }\end{array}$ \\
\hline 2 & $\begin{array}{l}\text { Before ileostomy } \\
\text { closure }\end{array}$ & 62 & 3 & 33 mo to date \\
\hline 3 & $\begin{array}{l}12 \text { mo after ileostomy } \\
\text { closure }\end{array}$ & 77 & 4 & 3 mo to date \\
\hline Mean (SD) & & $64.0(18.2)$ & $3.5(0.5)$ & \\
\hline
\end{tabular}

Table 1 Results of radial incision and cutting (RIC) for rectal anastomotic strictures.

SD, standard deviation. 

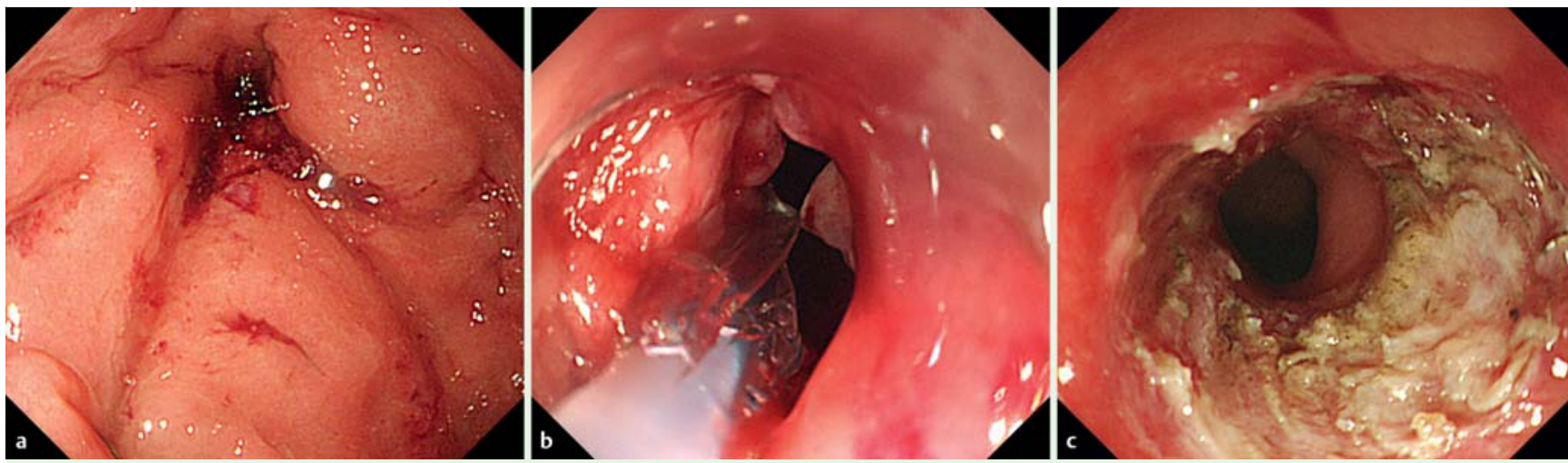

Fig. 2 Endoscopic images of patient 1, first session. a Anastomotic stricture before any endoscopic treatment. b Following several sessions of endoscopic balloon dilation up to a diameter of $15 \mathrm{~mm}$. c Anastomosis after successful completion of radial incision cutting. The connection between the proximal and distal sides of the stricture site in the rectal lumen is almost flat.

\section{Competing interests: None}

\section{Keita Harada', Seiji Kawano², Sakiko Hiraoka², Yoshiro Kawahara', Yoshitaka Kondo ${ }^{3}$, Hiroyuki Okada ${ }^{2}$}

${ }^{1}$ Okayama University Hospital, Division of Endoscopy, Okayama, Japan

2 Okayama University Graduate School of Medicine, Dentistry, and Pharmaceutical Sciences, Department of Gastroenterology and Hepatology, Okayama, Japan ${ }^{3}$ Okayama University Graduate School of Medicine, Dentistry, and Pharmaceutical Sciences, Department of Gastroenterological Surgery, Okayama, Japan

\section{References}

1 Kwon YH, Jeon SW, Lee YK. Endoscopic management of refractory benign colorectal strictures. Clin Endosc 2013; 46: $472-475$

2 Ragg J, Garimella V, Cast J et al. Balloon dilatation of benign rectal anastomotic strictures - a review. Dig Surg 2012; 29: $287-$ 291

3 Lamazza A, Fiori E, Sterpetti AV et al. Selfexpandable metal stents in the treatment of benign anastomotic stricture after rectal resection for cancer. Colorectal Dis 2014; 16: 0150-0153

4 Yano T, Yoda Y, Satake H et al. Radial incision and cutting method for refractory stricture after nonsurgical treatment of esophageal cancer. Endoscopy 2013; 45: 316-319

5 Muto M, Ezoe Y, Yano T et al. Usefulness of endoscopic radial incision and cutting method for refractory esophagogastric anastomotic stricture (with video). Gastrointest Endosc 2012; 75: 965 -972
Bibliography

DOI http://dx.doi.org/

10.1055/s-0034-1392861

Endoscopy 2015; 47: E552-E553

(c) Georg Thieme Verlag KG

Stuttgart · New York

ISSN 0013-726X

\section{Corresponding author}

\section{Keita Harada, MD}

Okayama University Hospital

Division of Endoscopy

2-5-1 Shikata-cho

Kita-ku

Okayama, 700-8558

Japan

Fax: +81-86-225-5991

keita818@cc.okayama-u.ac.jp 